\title{
STABILITY OF WAVE-DISSIPATING CONCRETE BLOCKS OF DEACHED BREAKWATERS AGAINST TSUNAMI
}

\author{
Minoru Hanzawa ${ }^{1}$, Akira Matsumoto ${ }^{2}$ and Hitoshi Tanaka ${ }^{3}$
}

\begin{abstract}
In Japan, detached breakwaters made with wave dissipating concrete blocks such as Tetrapods have been widely applied, but the effectiveness of such kinds of detached breakwaters on tsunami disaster prevention and stability of the structure have not been discussed in detail. Only few studies on wave run-up reduction were done after Nihonkai Chubu Earthquake Tsunami in 1983. In order to mitigate tsunami disasters in sea coast areas, the effectiveness of detached breakwaters and the stability of wave-dissipating concrete blocks should be properly evaluated. Authors has just studied on the effectiveness of detached breakwater on wave run-up reduction and wave pressure reduction on the seawall taking actually possible damage to detached breakwaters into account (Hanzawa et al., 2011). In this particular study, the hydraulic model tests have been systematically and carefully carried out to discuss the stability of wave-dissipating blocks of detached breakwater against solitary tsunami waves. Tetrapods of rear side of the breakwater tends to be damaged like land slide. The damage by tsunami is bigger than that by ordinary wind waves. A countermeasure for improving the stability is also proposed based on the damage process of detached breakwater.
\end{abstract}

Keywords: Coastal Structures, Wave-dissipating Concrete Block, Tsunami

\section{INTRODUCTION}

In recent years, the risk of occurrence of tsunamis generated by near shore earthquakes, such as, Tokai, Tonankai, Nankai and off-Miyagi had been considered to be higher and higher than before, as well as off shore tsunamis traveling long distances, e.g., the 2010 Chilean tsunami. And actually on March, 11th, 2011 the huge, devastating tsunami generated by the 2011 off the Pacific coast of Tohoku Earthquake attacked and damaged the huge area mainly in the east coast of Tohoku and Kanto in Japan. Although the concentrated efforts for recovery and rebuilding damaged coastal structures has been made since soon after the event had occurred, the prospect of completion of recovery is still invisible at the time of this paper is written.

The tsunami forces on vertical walls, such as seawalls, has already been studied in detail, e.g., Asakura et al.(2002), Kato et al.(2006), Mizutani and Imamura(2000).

Detached breakwaters are widely applied in front of seawalls especially in Japan. As for the effectiveness of detached breakwaters, only few studies on wave run-up reduction were done by eg., Uda et al.(1986) after Nihonkai Chubu Earthquake Tsunami in 1983, and Nakamura et al.(1998). The effects of reduction of wave pressure on the seawall behind detached breakwaters have not been studied. In the event of the Indian ocean tsunami in 2004, it was suggested that the detached breakwater surrounding Male island in the Maldives protected the island from inundation by the tsunami (Fujima et al., 2006). However, the phenomena was not utilized to formulate a design method.

In order to mitigate tsunami disasters in sea coast areas, the effectiveness of detached breakwaters should be properly estimated and consideration of the stability of concrete blocks against tsunami is inevitable.

In this context, authors already has just studied on the effectiveness of detached breakwater on wave run-up reduction and wave pressure reduction on the seawall taking actually possible damage to detached breakwaters into account (Hanzawa et al., 2011).

In this particular study, hydraulic model tests have been systematically and carefully carried out using solitary tsunami waves to evaluate the stability of wave-dissipating concrete blocks of detached breakwater following our previous study above. The counter measures to improve the stability of the concrete blocks against tsunamis proposed. In addition to the stability, the performance of detached breakwaters for wave run-up reduction taking actually possible concrete block movements into account to supplement the results obtained by the former study above.

\footnotetext{
${ }^{1}$ Fudo Tetra Corp., 7-2 Koamicho, Chuo-ku, Tokyo, 103-0016, Japan.

${ }^{2}$ Fudo Tetra Corp., 2-7 Higashi Nakanuki, Tsuchiura, 300-0006, Japan.

${ }^{3}$ Tohoku University, 6-6-06 Aoba, Sendai, 980-8579, Japan.
} 


\section{HYDRAULIC MODEL TESTS}

\section{Wave Flume Setup}

Figure 1 shows the wave flume setup. The wave flume is $30 \mathrm{~m}$ long, $0.5 \mathrm{~m}$ wide and $1.0 \mathrm{~m}$ deep. It is equipped with a piston type wave generator. The slope of $1 / 5$ begins at $\mathrm{x}=3.75 \mathrm{~m}$ and ends at $\mathrm{x}=4.25 \mathrm{~m}$. The slope of $1 / 30$ begins at $x=4.25 \mathrm{~m}$ and ends at $x=13.25 \mathrm{~m}$. The flat bed is constructed from $x=13.25 \mathrm{~m}$ to $14.75 \mathrm{~m}$ followed by a $1 / 20$ slope. Totally 13 wave gauges were installed from $\mathrm{x}=2.25 \mathrm{~m}$ to $14.25 \mathrm{~m}$ (St.1 to 13) for water surface monitoring as shown in Figure 1. However, wave gauge at No.9 was not allocated at the time of actual stability test with detached breakwater.

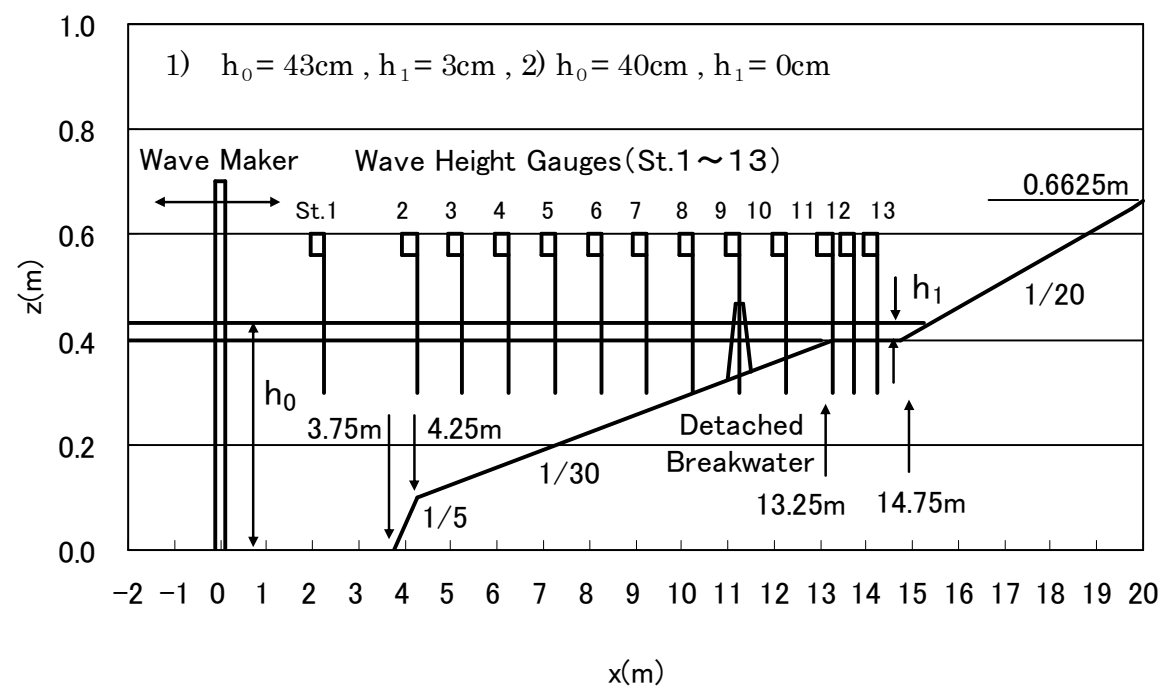

Figure 1. Wave flume setup.

\section{Detached Breakwater}

Figure 2 shows the cross section of the detached breakwater constructed in the flume for the test case with an off-shore water depth $\mathrm{h}_{0}=43 \mathrm{~cm}$ and water depth at the detached breakwater $\mathrm{h}=9.7 \mathrm{~cm}$. The center of the detached breakwater is set at $\mathrm{x}=11.25 \mathrm{~m}$ (St.9). The detached breakwater is made using wave-dissipating concrete blocks of Tetrapods of $59 \mathrm{~g}$. The crown width of the detached breakwater is equivalent to 3 rows of Tetrapod units. The crown height is set with a clearance of $\mathrm{hc}=4 \mathrm{~cm}$ above the sea water level which is set based on Japanese typical manner of $0.5 \mathrm{H}$ above sea water level, where $\mathrm{H}=8 \mathrm{~cm}$ is calculated based on the Hudson formula (Hudson, 1959) with $\mathrm{KD}=8.3$ for $59 \mathrm{~g}$ Tetrapods above.

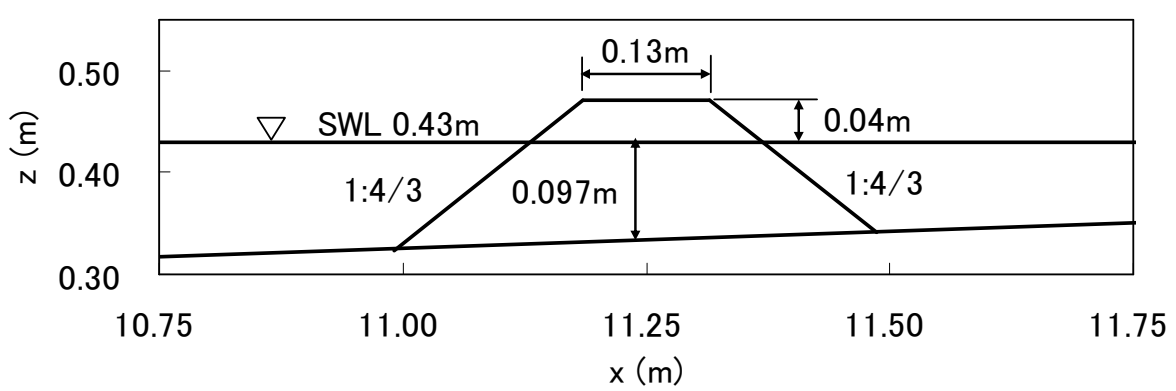

Figure 2. Cross section of detached breakwater (water depth at D.B.: $h=9.7 \mathrm{~cm}$ ) . 


\section{Damage Expression}

The damage of wave-dissipating concrete blocks has been conventionally expressed by $\mathrm{D}(\%)$, percentage of the number of damaged blocks against the total number of blocks. However, in our study, this method of count of damaged blocks is considered to be difficult, because a heavier damage should be analyzed for the situation of a tsunami disaster. Therefore, the damage parameter S proposed by van der Meer(1987) is used in our study. S is calculated as Ae/ $\mathrm{Dn}^{2}$ (Ae: eroded area of cross section, $\mathrm{Dn}=\mathrm{V}^{1 / 3}, \mathrm{~V}$ : volume of Tetrapod unit). Figure 3 shows the definition of damage based on this van der Meer method. Figure 4 shows the measuring points to calculate the cross-sectional change of the detached breakwater.

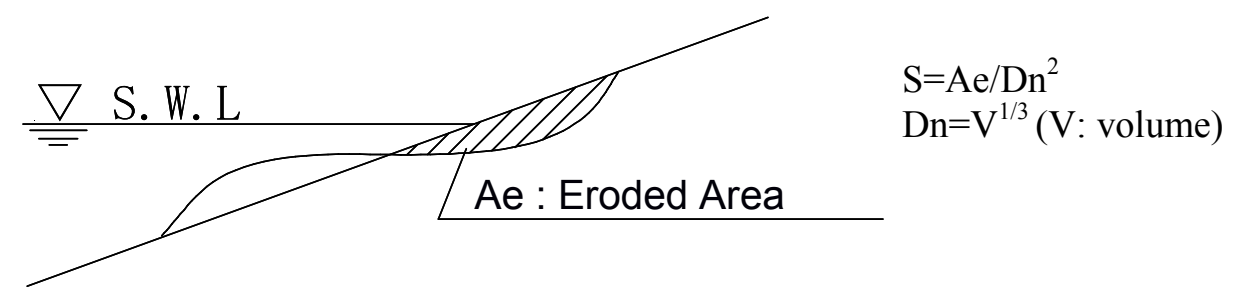

Figure 3. Definition of Damage of Detached Breakwaters.

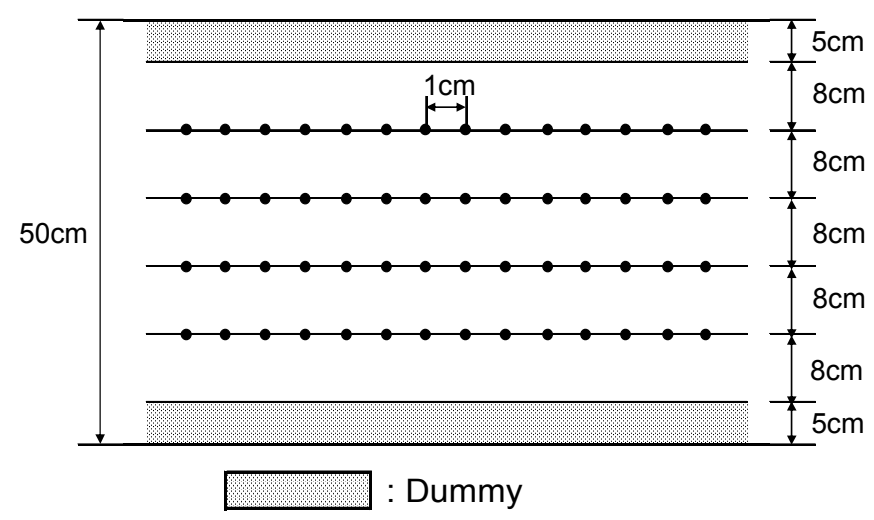

Figure 4. Measruing Points of Cross-Sectional Change.

\section{Test Cases}

Table 1 shows the hydraulic model test cases. Case A and B are the test cases with water depth at the detached breakwater $\mathrm{h}=9.7 \mathrm{~cm}$ (off-shore water depth at wave generator $\mathrm{h}_{0}=43 \mathrm{~cm}$ ) and $\mathrm{h}=6.7 \mathrm{~cm}$ $(\mathrm{h} 0=40 \mathrm{~cm})$, respectively. In our study the crest heights of $\mathrm{hc}=8.0 \mathrm{~cm}$ and $12.0 \mathrm{~cm}$ were also tested in addition to the base case with $\mathrm{hc}=4 \mathrm{~cm}$ in order to analyze the influence of crest height on the stability of wave-dissipating concrete blocks. And Tetrapod masses of $98.6 \mathrm{~g}$ and $125.0 \mathrm{~g}$ were also tested in addition to the base case of $58.9 \mathrm{~g}$ in order to verify the effect of mass increase on stability of wavedissipating concrete blocks.

In our study, solitary waves are generated for the stability tests as the one of the tsunami wave condition as the first step of the research on the stability of the wave-dissipating concrete blocks against tsunamis. The offshore wave height in front of the wave paddle at $S t .1$ in Figure 1 was $1 \mathrm{~cm}$ to $9 \mathrm{~cm}$ and the wave height at the breakwater St.9 was up to about $15 \mathrm{~cm}$.

The detached breakwater was reconstructed after every wave generation and cross-sectional change measurement as explained in the previous section. 
Table 1. Hydraulic Model Test Cases.

\begin{tabular}{|c|c|c|c|}
\hline Case & $\begin{array}{l}\text { Water Depth } \\
\text { at D.B. h }(\mathrm{cm})\end{array}$ & $\begin{array}{l}\text { Crest Hight } \\
\text { hc }(\mathrm{cm})\end{array}$ & $\begin{array}{c}\text { Mass of TP } \\
M(g)\end{array}$ \\
\hline$A-1-1$ & \multirow{9}{*}{9.7} & \multirow{3}{*}{4.0} & 58.9 \\
\hline$A-1-2$ & & & 98.6 \\
\hline$A-1-3$ & & & 125.0 \\
\hline$A-2-1$ & & \multirow{3}{*}{8.0} & 58.9 \\
\hline$A-2-2$ & & & 98.6 \\
\hline$A-2-3$ & & & 125.0 \\
\hline A-3-1 & & \multirow{3}{*}{12.0} & 58.9 \\
\hline A-3-2 & & & 98.6 \\
\hline A-3-3 & & & 125.0 \\
\hline B-1-1 & 6.7 & 4.0 & 58.9 \\
\hline
\end{tabular}

\section{TESTS RESULTS AND DISCUSSIONS}

\section{Cross Sectional Change}

Figure 5 shows examples of stability test result as change of cross section of detached breakwater before and after tsunami wave attack for the test case with water depth at the detached breakwater $\mathrm{h}=6.7 \mathrm{~cm}$. In the figures $\eta \max$ is the incident wave height at St.9 measured under the condition without breakwater. $\mathrm{S}$ is the damage parameter $\left(=\mathrm{Ae} / \mathrm{Dn}^{2}\right.$, Ae: eroded area of cross section, $\mathrm{Dn}:=\mathrm{V}^{1 / 3}: \mathrm{V}$ is volume of Tertapod) proposed by van der Meer (1987) and D is the percentage of damaged blocks against total number of blocks as explained before. As shown in the figures, the part of rear slope of the detached breakwater is damaged. $\eta$ max, $\mathrm{S}$ and $\mathrm{D}$ of figures (a) and (b) are $6.9 \mathrm{~cm}, 1.27,4.1 \%$ and $11.4 \mathrm{~cm}, 3.74,19.7 \%$ respectively. As for Case (a) KD is calculated as 4.1 with the damage of $\mathrm{D}=4.1 \%$. On the other hand, $1 \%$ damage is expected with ordinary wind wave height as $\mathrm{KD}=8.3$. This means that the damage by tsunami is bigger compared with ordinary wind wave.

Wave-dissipating concrete blocks are usually relocated unit by unit when damaged by ordinary wind waves. And the damaged sections are the shoulders of front/rear slopes and the crest. On the other hand, as for the tsunami waves, detached breakwater tends to be damaged mainly around the rear slope and just after water surface reaches highest level resulting in relocation of Tetrapods like land slide. This manner of damage is very important to be discussed later from the view point of the flow field to give hints for improvement of the stability of wave-dissipating concrete blocks of detached breakwater against tsunamis.

Figure 6 shows the test results as relation between $\eta$ max and $S$ for the cases with water depth at detached breakwater $\mathrm{h}=9.7 \mathrm{~cm}$. The abscissa is normalized by the nominal size of Tetrapod Dn. Figures (a), (b) and (c) correspond to the cases with crown heights $h \mathrm{c}=4,8$ and $12 \mathrm{~cm}$. Each figure shows the results for the base case with Tetrapod of mass of 58.9g comparing with those for additional cases with $98.6 \mathrm{~g}$ and $125.0 \mathrm{~g}$.

As shown in the figure, the heavier the mass, the smaller the damage as naturally expected and the linear tendency of relation between $S$ and $\eta \max /$ Dn can be observed. The effect of bigger crown height on the Tetrapod stability can be also observed. However, the mass increase is considered to have more effective than crown height. 
Figure 7 and 8 show the comparison of the test results from the test cases with water depth at the breakwater $\mathrm{h}=9.7 \mathrm{~cm}$ and $6.7 \mathrm{~cm}$. The mass of Tetrapod and the crown height are $\mathrm{M}=58.9 \mathrm{~g}$ and $\mathrm{hc}=4 \mathrm{~cm}$ respectively for both cases.

The abscissa of Figure 7 is $\eta \max / \mathrm{Dn}$ as same as Figure 6. It can be seen that the smaller the depth, the bigger the damage. It is considered that if the tsunami height is the same, the inflow water volume can be the same level resulting higher velocity in the shallow case to cause bigger damage to the detached breakwater.

In Figure 8 , the abscissa is $\eta \max / \mathrm{h}$. The data cloud of Figure 8 is considered smaller compare with that of Figure 7. From these results, it is implied that the velocity increase and damage of detached breakwater can be possibly expressed by this parameter of $\eta \max / \mathrm{h}$.

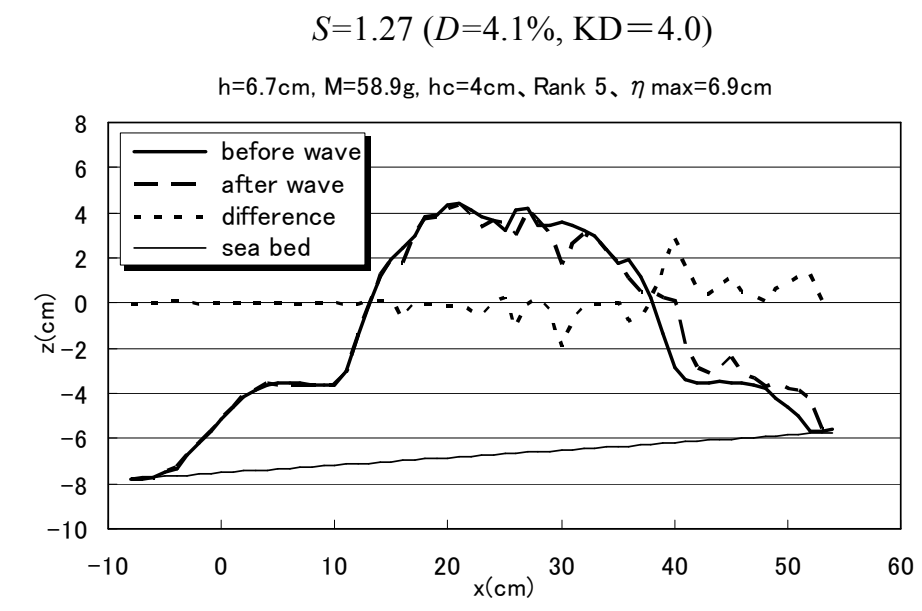

(a) $\eta \max =6.9 \mathrm{~cm}$

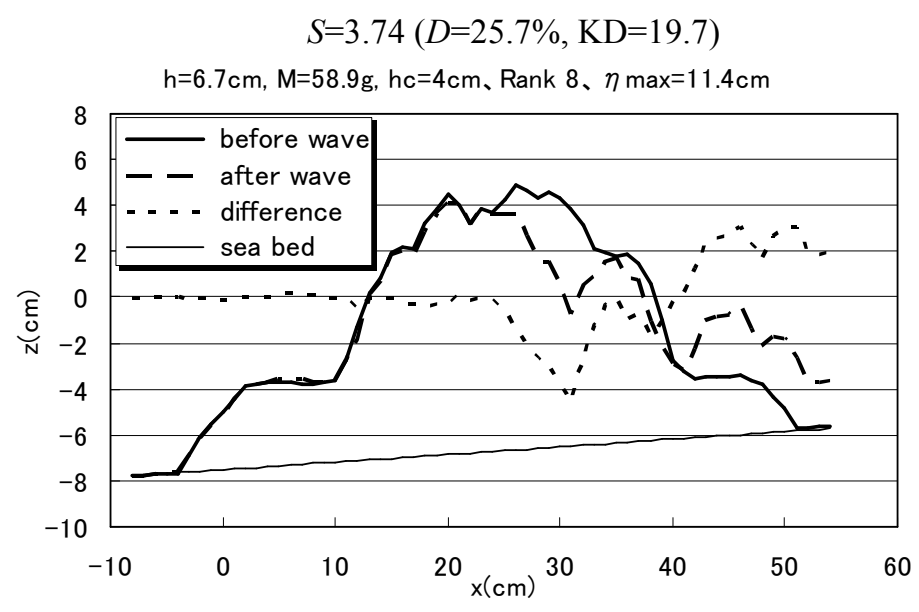

(b) $\eta_{\max }=11.4 \mathrm{~cm}$

Figure 5. Examples of cross sectional change before and after tsunami wave attack 


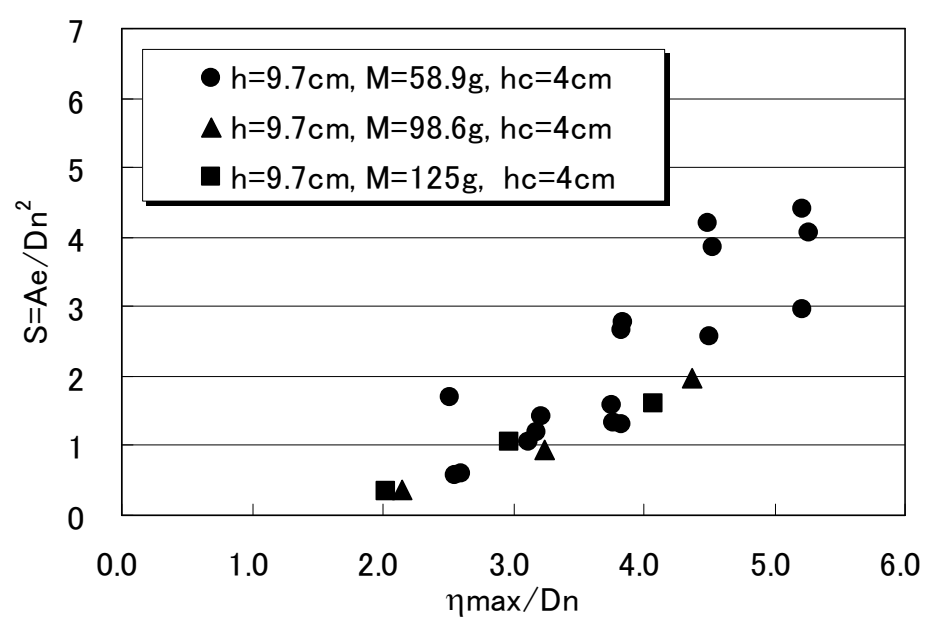

(a) $\mathrm{hc}=4 \mathrm{~cm}$

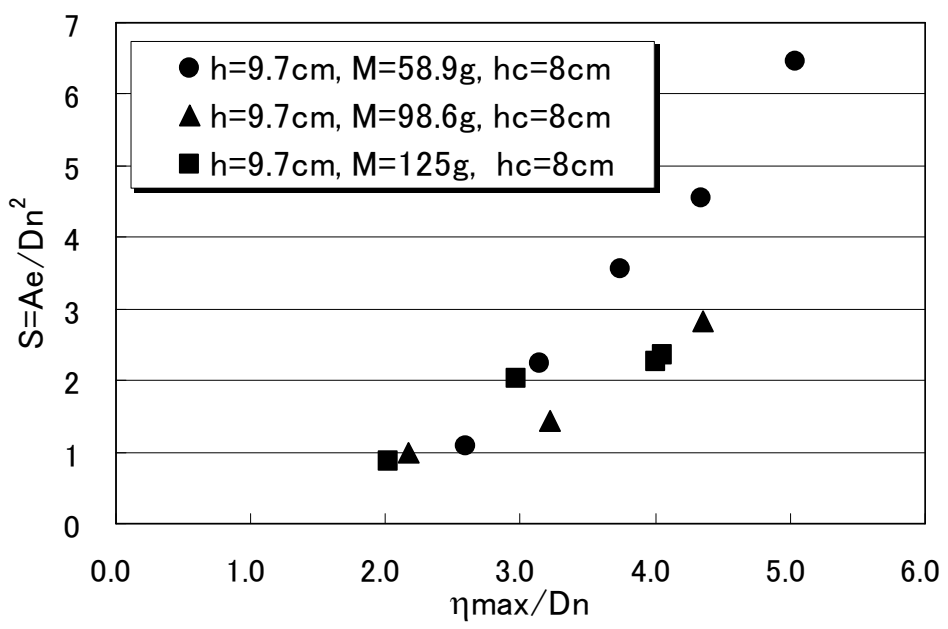

(b) $\mathrm{hc}=8 \mathrm{~cm}$

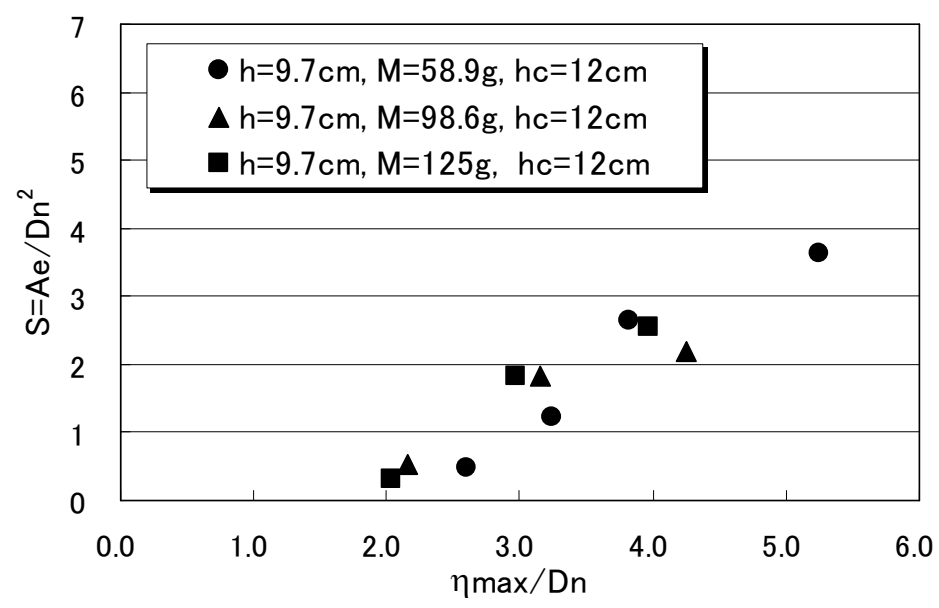

(c) $\mathrm{hc}=12 \mathrm{~cm}$

Figure 6. Relation between $\eta$ max and $S(h=9.7 \mathrm{~cm})$. 


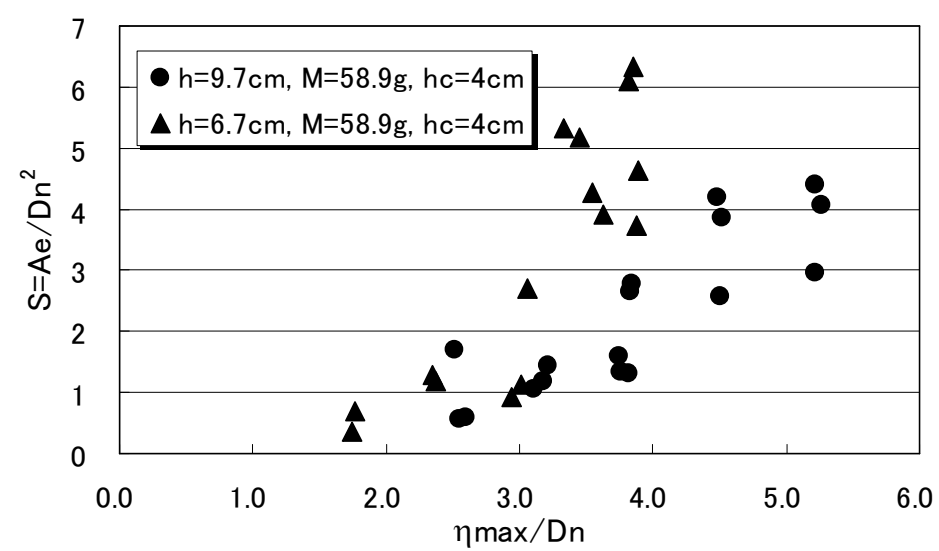

Figurer 7. Relation between $\eta \max / \mathrm{Dn}$ and S.

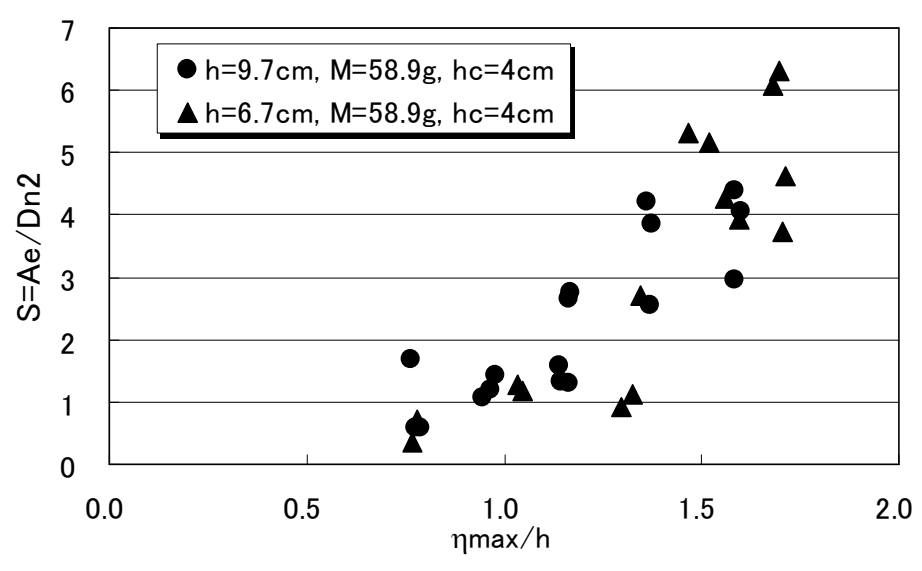

Figurer 8. Relation between $\mathrm{nmax} / \mathrm{h}$ and $\mathrm{S}$.

\section{Analysis of Flow Field by CADMAS-SURF}

In this section, the flow field in and around the detached breakwater is analyzed by using numerical simulation. CADMAS-SURF (Isobe et., al., 1998, 2002), one of the VOF method (Hurt, 1981) was used. The flow fields under the conditions of the solitary tsunami wave are simulated. Figure 9 (a) shows the time series of the water surface change calculated at the center of the detached breakwater. Figure 9 (b), (c) and (d) show the velocity vectors in and around the detached breakwater at the time when the water level at the center of detached breakwater is the maximum and 0.2 and 0.4 seconds after the peak time respectively. As shown in the figures, the very high downward velocity along the rear slope of the detached breakwater can be seen just after the water level reaches highest under the solitary tsunami wave. This specific condition of flow field is considered to clearly corresponds to the phenomena of movement of Tetrapods like land slide under the solitary tsunami wave. 
(b) (c) (d)

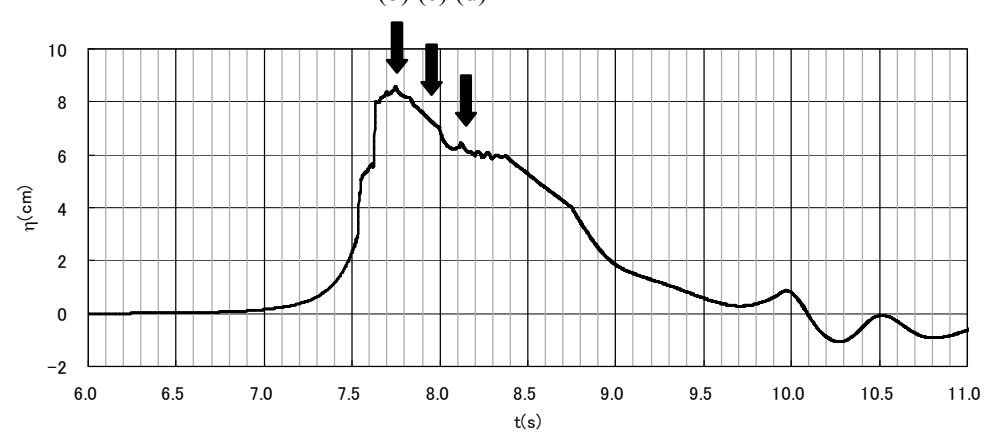

(a) Time series of the water surface change at the center of the detached breakwater

$0.5 \mathrm{~m} / \mathrm{s}$

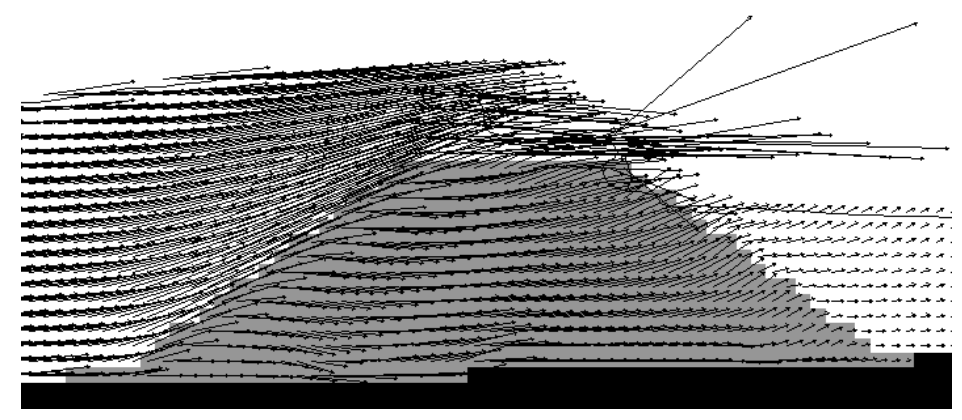

(b) $t=$ tpeak (at water level peak)

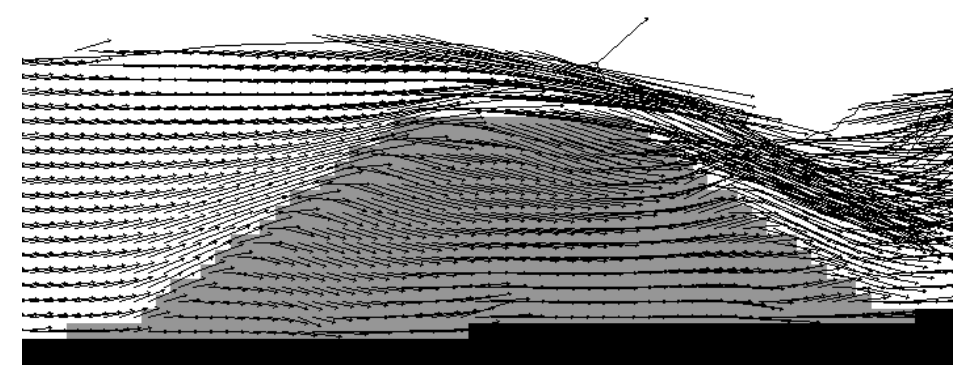

(c) $\mathrm{t}=$ tpeak $+0.2 \mathrm{~s}$

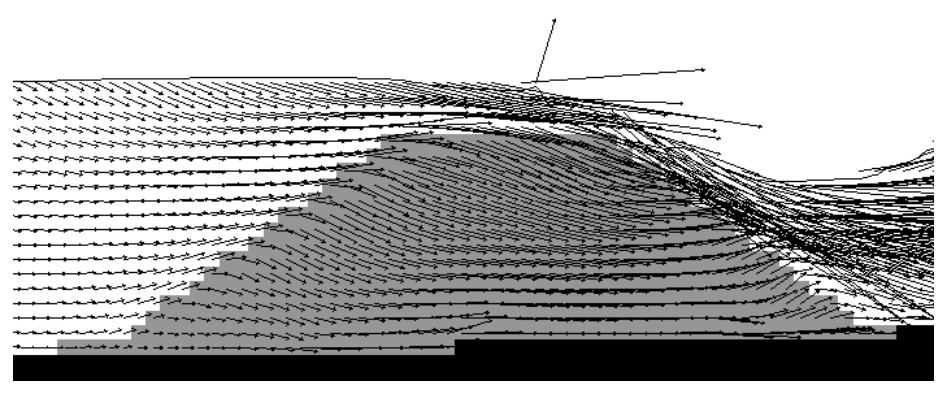

(d) $\mathrm{t}=$ tpeak $+0.4 \mathrm{~s}$

Figurer 9. Water velocity calculated by CADMAS-SURF. 


\section{Improvement of Stability}

As discussed previously, detached breakwater made with wave-dissipating concrete blocks tends to be damaged by solitary tsunami wave like a land sliding. This phenomenon can be explained by the very high downward velocity along the slope of the detached breakwater calculated by CADMAS-SURF previously. Based on this phenomenon, an additional hydraulic model test was carried out to improve the stability of the detached breakwater. In this test case, the first row of Tetrapods of the rear side of the detached breakwater was fixed by a wire. Figure 10 (a) and (b) show the results of the test cases with and without the fixing the first row of the detached breakwater respectively. As shown in the figures, the stability of the detached breakwater can be drastically improved by the fixing the first row of rear side of the breakwater.

As explained above, the first row of the breakwater was fixed by a wire in the test. As for the practical measure for fixing at site, many alternatives can be considered. For example, driving steel pipe piles or placing heavy flat type concrete blocks close to the first row of Tetrapods. However, further consideration shall be done such as wave force on to steel pipe piles, etc., in order to practically realize those ideas.

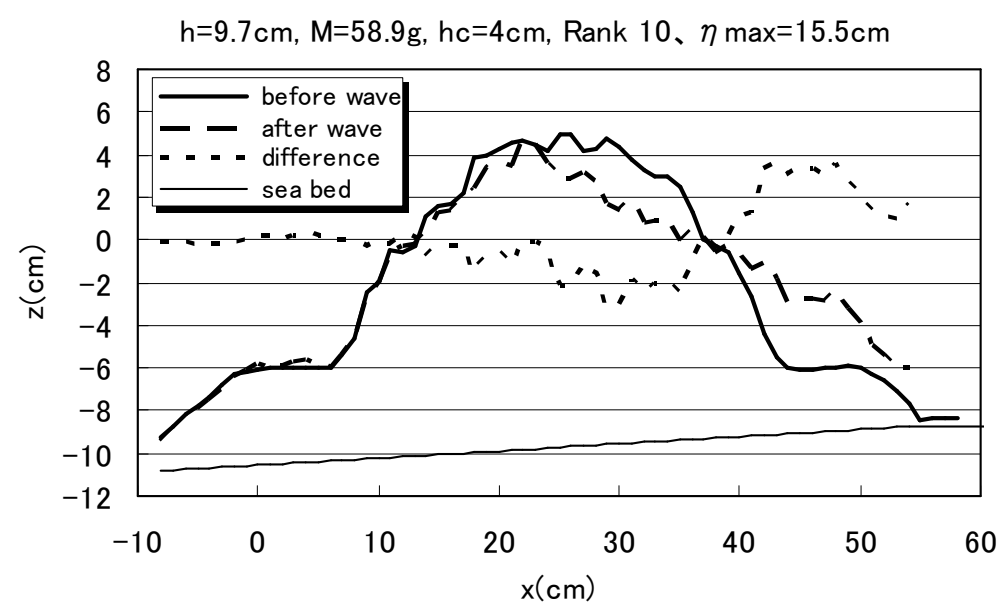

(a) without improvement

$\mathrm{h}=9.7 \mathrm{~cm}, \mathrm{hc}=4 \mathrm{~cm}, \mathrm{M}=58.9 \mathrm{~g}$, Rank $10 、 \eta \max =15.1 \mathrm{~cm}$

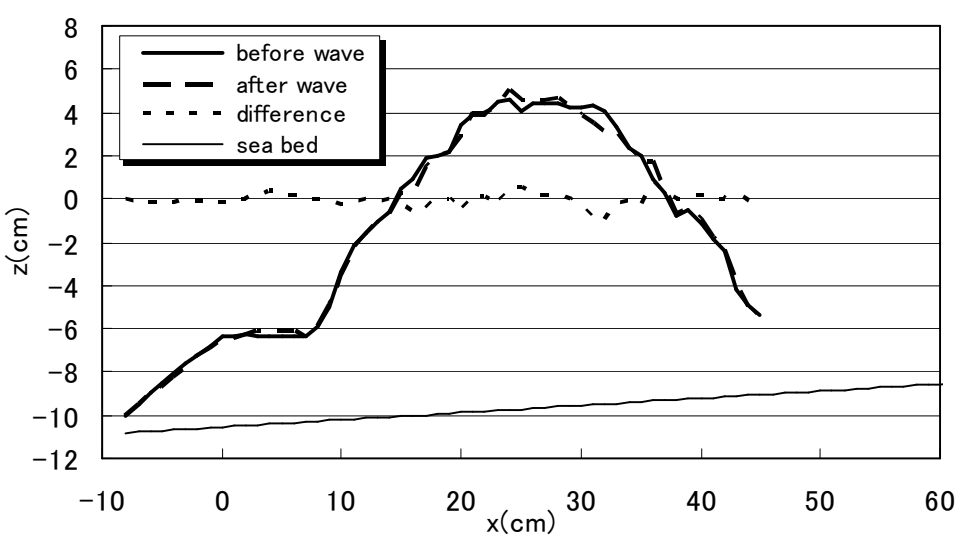

(b) with improvement by fixing the first row of rear side

Figurer 10. Stability improvement. 


\section{Reduction of Tsunami Wave Run-up}

The effect $f$ detached breakwater to reduce the run-up was experimentally studied by authors (Hanzawa, et.al., 2011) Wave-dissipating concrete blocks were fixed by nets to avoid displacement of blocks at the time of the wave run-up tests in the former study above. The damaged breakwater was simulated by using cross section of under water type. But, in reality, blocks might be damaged during receiving the wave. In this study additional hydraulic model tests were carried out to evaluate the effect on reduction of wave run-up taking the actually possible damage into account.

Figure 11 shows the results of hydraulic model tests. The plots of $\square, \bigcirc, \triangle$ are represent the test cases without detached breakwater, with full type breakwater and the underwater type respectively. The plots of $\downarrow$ are describe the cases with full type allowing block movement.

Even if the blocks are moved, effect on run-up reduction is the same as the case without block movement.
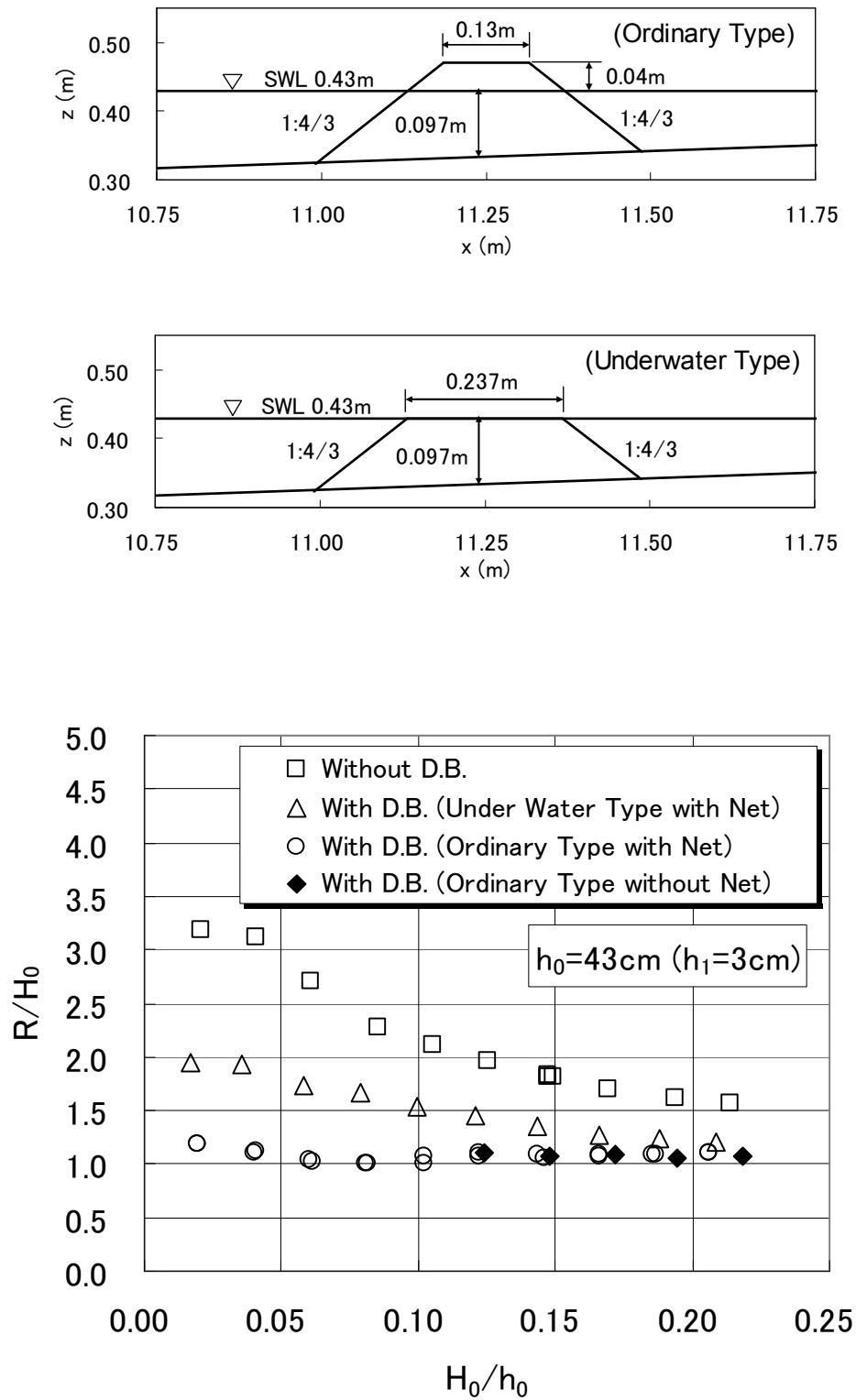

Figurer 11. Wave run-up reduction effect. 


\section{CONCXLUSIONS}

In this study, hydraulic model tests have been systematically and carefully carried out using solitary tsunami waves to evaluate the stability of concrete blocks of detached breakwater. The main results from our study this time are summarized as follows:

1) Tetrapods at rear slope of detached breakwaters are mainly damaged by solitary tsunami waves rather than front side.

2) Detached breakwater tends to be damaged after water surface reaches highest level resulting in relocation of Tetrapods like land slide.

3) Mass of Tetrapod calculated based on Hudson formula using design wind wave is not sufficient to be stable against same wave height of solitary tsunami wave.

4) Shallow depth causes heavier damage to detached breakwater compared with that in deeper water if the wave height is the same.

5) Relative wave height to water depth at detached breakwater might possibly be parameter to formulate damage of breakwaters.

6) The stability of detached breakwater can be drastically improved by fixing the first row of rear side of the breakwater.

7) Even if the blocks are moved, effect on run-up reduction is the same as the case without block movement.

The stability of detached breakwater made with wave-dissipating concrete blocks against solitary tsunami waves were studied by systematic hydraulic model tests as the first step. Authors would like to continue this research by carrying out more hydraulic model tests to formulate the relation between the stability of the detached breakwater and the tsunami wave height.

\section{REFERENCES}

Asakura, R., Iwase K., Ikeya T., Takao M., Kaneto T., Fujii N. and Ohmori M. 2002. The tsunami wave force acting on land structures, Proceedings of the $28^{\text {th }}$ International Conference on Coastal Engineering, ASCE, 1191-1202.

Fujima, K., Shigihara, Y., Tomita, T., Honda, K., Nobuoka, H., Hanzawa, M., Fujii, H., Ohtani, H., Orishimo, S., Tatsumi, M. and Koshimura, S. 2006. Survey results of Indian Ocean Tsunami in the Maldives, Coastal Engineering Journal, Vol. 48, No.2, JSCE, 81-97.

Hanzawa, H., Matsumoto, A. and Tanaka, H. 2011. Experimental Research on Detached Breakwaters' Effect on Tsunami Disaster Mitigation, Proceedings of Coastal Structures 2011, ASCE (in printing)

Hudson, R.Y. 1959. Laboratory Investigation of Rubble-mound Breakwater, Proceedings of ASCE, Vol.85, WW3, 93-121.

Hirt, C. and B.D. Nichol. 1981. Volume of Fluid (VOF) Method for Dynamics of Boundaries, Journal of Computational Physics, Vol. 39, 201-205.

Isobe, M., Y. Hanahara, Y. Xiping and S. Takahashi. 2002. Numerical Simulation of Waves Overtopping a Breakwater, Proceedings of the $28^{\text {th }}$ International Conference on Coastal Engineering, ASCE, 2273-2285.

Isobe, M., Y. Xiping,.Umemura and S. Takahashi. 1999. Study on Development of Numerical Wave Flume, Proceedings of Coastal Engineering, vol.46, JSCE , 36-40. (in Japanese).

Kato, F., Inagaki, S.and Fukuhama, M. 2006. Wave Force on Coastal Dike due to Tsunami, Proceedings of the 30 ${ }^{\text {th }}$ International Conference on Coastal Engineering, ASCE, 5150-5161.

Mizutani, M and Imamura, F. 2000. Hydraulic Experimental Study on Wave Force of a Bore Acting on Structure, Proceedings of Coastal Engineering, vol.47, JSCE, 946-950. (in Japanese) 
Nakamura, K., Sasaki, T. and Nakayama, A. 1998. Hydraulic Model Study on Reduction of Run-up of Tsunami by Coastal Structures, Proceedings of Civil Engineering in Ocean, vol.14, JSCE, 293-298. (in Japanese).

Togashi, M., Hirayama, Y., Kawano, T. and Soda, Y. 1986. On Scattering Mechanism of Concrete Blocks Due to Tsunami Run-up with Soliton Dispersion, Proceedings of Coastal Engineering, vol.33, JSCE, 466-470. (in Japanese).

Togashi, M., Y. Hirayama, and M. Sugiyama. 1987. Damaging Mechanism of Precast Concrete Armour Unit Dikes Due to Tsunami Run-up with Soliton Dispersion, Proceedings of Coastal Engineering, vol.34, JSCE, 517-521. (in Japanese).

Uda, T., Omata, A. and Yokoyama, Y. 1986. Effect of Detached Breakwaters against Tsunami Run-up on the Beach, Proceedings of Coastal Engineering, vol.34, JSCE, 461-465. (in Japanese).

van der Meer, J.W. 1987. Stability of breakwater armor layers-Design formulae, Coastal Engineering, $11,219-239$. 